\title{
The effect of different methods and image analyzers on the results of the in vivo comet assay
}

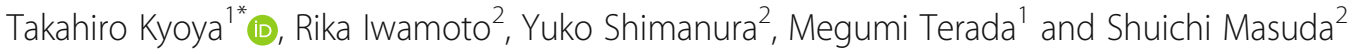

\begin{abstract}
Introduction: The in vivo comet assay is a widely used genotoxicity test that can detect DNA damage in a range of organs. It is included in the Organisation for Economic Co-operation and Development Guidelines for the Testing of Chemicals. However, various protocols are still used for this assay, and several different image analyzers are used routinely to evaluate the results. Here, we verified a protocol that largely contributes to the equivalence of results, and we assessed the effect on the results when slides made from the same sample were analyzed using two different image analyzers (Comet Assay IV vs Comet Analyzer).

Findings: Standardizing the agarose concentrations and DNA unwinding and electrophoresis times had a large impact on the equivalence of the results between the different methods used for the in vivo comet assay. In addition, there was some variation in the sensitivity of the two different image analyzers tested; however this variation was considered to be minor and became negligible when the test conditions were standardized between the two different methods.

Conclusion: By standardizing the concentrations of low melting agarose and DNA unwinding and electrophoresis times between both methods used in the current study, the sensitivity to detect the genotoxicity of a positive control substance in the in vivo comet assay became generally comparable, independently of the image analyzer used. However, there may still be the possibility that other conditions, except for the three described here, could affect the reproducibility of the in vivo comet assay.
\end{abstract}

Keywords: Image analyzer, Comet assay IV, Comet analyzer, Validation, \% tail DNA, EMS

\section{Introduction}

The single cell gel electrophoresis, or comet, assay is a genotoxicity test that, is able to detect DNA damage at the single-cell level [1]. It can be performed in vivo and in vitro and detects double and single strand breaks, alkaline labeling sites, oxidative-based damage, unrepaired DNA lesions and crosslink sites [2-5]. In vivo, it has the added advantage of detecting the organ-specific genotoxicity of chemicals.

The in vivo comet assay using rodents is widely recognized as a useful tool to assess genotoxicity; however, there is great variation in the protocol used [2]. This can have an important effect on the results of the assay [6], and a standardized method is needed to detect genotoxic

\footnotetext{
* Correspondence: t-kyoya@kumiai-chem.co.jp

${ }^{1}$ Life Science Research Institute, Kumiai Chemical Industry Co., Ltd, 3360

Kamo, Kikugawa-shi, Shizuoka 439-0031, Japan

Full list of author information is available at the end of the article
}

substances with a high degree of accuracy and reproducibility. Therefore, based on the available literature, such a standard protocol was developed in Japan [4, 7-10]; it was used for the international validation of the in vivo comet assay. It was widely appreciated by the international scientific community and allowed the inclusion of the in vivo comet assay using rats in the Organisation for Economic Co-operation and Development (OECD) test guidelines (TG489). This standard protocol was adopted by a number of companies and contract research organizations. However, the choice of protocols used to perform the in vivo comet assay is decided by each institute. In addition, different image analyzers are used to evaluate the results of the comet assay [11-13].

Given this variability in the protocols and analyses used to perform the in vivo comet assay, it is of concern that the results for the same substance will change significantly among the different approaches used. Even 
within the same research institution, data for a given substance may be inconsistent if different protocols are used to obtain them. In this context, there is a case for the continued use of a specific and established protocol in order to guarantee the consistency of new and historical data obtained by each institute, thus allowing institutes to take advantage of their historical data.

It is necessary to understand which of the differences between the various protocols affect the results of the in vivo comet assay. Likewise, it is important to gauge the effects of the image analyzer used on the test results. Here, we therefore conducted two different protocols of the in vivo comet assay using tissue isolated from individual animals and investigated which method should be standardized to obtain equivalent results in different protocols. In addition, we investigated the effect of different protocols and image analyzers on the results of the in vivo comet assay.

\section{Materials and methods Materials}

Ethyl methanesulfonate (EMS, CAS No. 62-50-0; Wako Pure Chemical Industries, Ltd., Tokyo, Japan) was used as a genotoxic positive control substance [14]. Physiological saline (PS) was used as a solvent (Otsuka Pharmaceutical Factory, Inc., Tokyo, Japan). Low melting agarose (LMA, NuSieve GTG) was purchased from Lonza (Basel, Switzerland), and standard melting agarose (SMA, Ultra Pure ${ }^{\mathrm{m}}$ Agarose) was purchased from Thermo Fisher Scientific, Inc. (Massachusetts, USA). SYBR gold was purchased from Thermo Fisher Scientific, Inc. (Massachusetts, USA). Ethidium bromide (EtBr) was purchased from Wako Pure Chemical Industries, Ltd. (Tokyo, Japan).

\section{Animals}

Six week-old male Sprague-Dawley rats (Slc:SD) were supplied by Japan SLC, Inc. (Shizuoka, Japan) and acclimatized for 5 days prior to the experiments. Their age at the start of the experiment was 6-7 weeks. The rats were maintained on a 12 light/dark cycle at $24.5 \pm 0.5^{\circ}$ C. They were fed a standard diet (CE-2; CLEA Japan, Inc., Tokyo, Japan) and were given tap water ad libitum.

\section{Treatment of animals}

Rats in the treatment group $(N=4)$ were given 2 doses of EMS $(200 \mathrm{mg} / \mathrm{kg})$ in PS by oral gavage at 24 and $3 \mathrm{~h}$ before necropsy. Rats in the negative control group $(N=4)$ were treated in the same way, but given PS only.

\section{Image analyzers}

A Comet Assay IV (Perceptive Instruments Ltd., Suffolk, UK) and a Comet Analyzer (Youworks Co., Tokyo, Japan) were used for image analysis. The parameter measured for comparison was \% tail DNA. For measurements conducted using the Comet Analyzer, \% tail DNA was calculated from the tail moment parameter, according to the manufacturer's instructions.

We compared two different protocols for tissue preparation: the standard protocol of the international validation of the in vivo comet assay (Method 1) and a protocol based on a previously published paper (Method 2) [4]. To gain a better insight into which parameters of the protocols had the greatest impact on the results, we introduced a stepwise modification of Method 2 to bring it closer to Method 1. In Study 1, the original methods were used as reported $[4,10]$. Next, we adjusted the LMA concentrations of Method 2 to those of Method 1 (Study 2). Finally, in Study 3, in addition to LMA concentration, we adjusted the DNA unwinding and electrophoresis times of Method 2 to match those of Method 1.

\section{Tissue preparation for method 1 (standard protocol [10])}

The rats were euthanized at $3 \mathrm{~h}$ after the second EMS or control treatment. Three or 4 cubes with an approximate side length of $5 \mathrm{~mm}$ were isolated from the left lateral lobe of the liver. The samples were minced in $3 \mathrm{~mL}$ cold mincing buffer of $20 \mathrm{mM}$ ethylenediaminetetraacetic acid disodium salt (EDTA-2Na), 10\% dimethyl sulfoxide (DMSO), and Hank's balanced salt solution $\left(\mathrm{Ca}^{2}\right.$ ${ }^{+}$-and $\mathrm{Mg}^{2+}$-free) at $\mathrm{pH} 7.5$ using dissection scissors. The samples were stored on ice for $30 \mathrm{~s}$ to allow large clumps to settle. Next, $10 \mu \mathrm{L}$ of the supernatant were dispensed into a new $1.5 \mathrm{~mL}$ micro tube on ice. To this, $90 \mu \mathrm{L}$ of $0.5 \%$ LMA in Dulbecco's phosphate-buffered saline (DPBS) were added, and the mix was dripped onto a glass slide (Matsunami Grass Ind. Ltd., Osaka, Japan) coated with 1\% SMA with DPBS. To facilitate an even spread of the mixture across the slide, it was covered quickly with another slide. After the agarose had solidified at $4{ }^{\circ} \mathrm{C}$, the slides were separated, and another $90 \mu \mathrm{L}$ of $0.5 \%$ LMA were added immediately in order to embed the cell layer fully in the agarose using another slide. In this way, 4 slides were prepared for each animal. After the top agarose layer had solidified, the slide was placed in a lysing solution of $2.5 \mathrm{M} \mathrm{NaCl}, 100 \mathrm{mM}$ EDTA-2Na, $10 \mathrm{mM}$ Tris-hydroxymethyl aminomethane (Tris), 1\% Triton $\mathrm{X}-100$, and 10\% DMSO at pH 10 and left overnight in a cool and dark place. The slide was then rinsed with purified water and immersed in an alkaline solution of $300 \mathrm{mM} \mathrm{NaOH}$ and $1 \mathrm{mM}$ EDTA$2 \mathrm{Na}$ for $20 \mathrm{~min}$ to unwind the DNA. Electrophoresis was carried out for $20 \mathrm{~min}$ at a voltage of $23 \mathrm{~V}(0.7 \mathrm{~V} /$ $\mathrm{cm})$ and a current of $300 \mathrm{~mA}$. Following this, the sample was neutralized by dripping an appropriate quantity of $400 \mathrm{mM}$ Tris buffer ( $\mathrm{pH}$ 7.5) onto the slide. After 
approximately $10 \mathrm{~min}$, the slide was immersed in ethanol $(\geq 99.6 \%)$ for more than $5 \mathrm{~min}$ to achieve dehydration. Approximately $60 \mu \mathrm{L}$ SYBR Gold (Thermo Fisher Scientific, Massachusetts, USA), diluted 5000-fold with Tris/EDTA buffer ( $\mathrm{pH} 8.0$ ), were dripped onto the slide, which was then covered with a cover slip and observed through an epi-illumination fluorescence microscope. \% tail DNA was measured for 50 randomly chosen cells per slide using the Comet Assay IV, and the median \% tail DNA for 50 cells per slide was calculated. The average median for 2 slides was used as the DNA damage parameter for each animal. Cells with heads that were extremely small (\% tail DNA $\geq 90 \%$, "hedgehogs") or irregularly shaped due to cytotoxicity, and which thus deviated substantially from the comet shape, were excluded from the analysis.

\section{Tissue preparation for method 2 (adapted from [4])}

Following the same procedure as for Method 1, 3 or 4 cubes with an approximate side length of $5 \mathrm{~mm}$ were isolated from the left lateral lobe of the liver. The samples were minced in $3 \mathrm{~mL}$ of cold mincing buffer of $30 \mathrm{mM}$ EDTA-2Na and $0.9 \%(w / v) \mathrm{KCl}$ at $\mathrm{pH} 7.5$, using dissection scissors. Following this, the samples were stored on ice for $30 \mathrm{~s}$ to allow large clumps to settle. Next, $75 \mu \mathrm{L}$ of the cell suspension were mixed with $75 \mu \mathrm{L} 1.4 \%$ LMA in DPBS, and $75 \mu \mathrm{L}$ of this mix $(0.7 \%$ LMA) were dripped onto a slide coated with $0.7 \%$ SMA in DPBS, which was covered quickly with another slide to spread the mixture evenly across the slide. After the agarose had solidified at $4{ }^{\circ} \mathrm{C}$, the slides were separated, and $75 \mu \mathrm{L}$ of $0.7 \%$ LMA was dripped immediately onto the slide again to embed the cell layer fully in the agarose using another slide. Four slides were prepared for each animal. After the top layer of agarose had solidified, the slide was placed in a lysing solution $(\mathrm{pH} 10)$ of $2.5 \mathrm{M} \mathrm{NaCl}, 100 \mathrm{mM}$ EDTA-2Na, $10 \mathrm{mM}$ Tris, $1 \%$ sodium lauroyl sarcosinate $(w / v), 1 \%$ Triton X-100, and $10 \%$ DMSO and left overnight in a cool and dark place. The next day, the slide was immersed in an alkaline solution of $300 \mathrm{mM} \mathrm{NaOH}$ and $1 \mathrm{mM}$ EDTA-2Na for $10 \mathrm{~min}$ to unwind the DNA. Electrophoresis was carried out for $15 \mathrm{~min}$ at a voltage of $25 \mathrm{~V}(0.96 \mathrm{~V} / \mathrm{cm})$ and a current of $300 \mathrm{~mA}$. Following this, the slide was neutralized by immersing it in $400 \mathrm{mM}$ Tris buffer ( $\mathrm{pH}$ 7.5) for approximately $10 \mathrm{~min}$. Next, the slide was immersed in ethanol $(\geq 99.6 \%)$ for more than $10 \mathrm{~min}$ to dehydrate the sample. Approximately $30 \mu \mathrm{L}$ of $20 \mu \mathrm{g} / \mathrm{mL} \mathrm{EtBr}$ was dripped onto the slide, which was then covered with a cover slip and observed through an epi-illumination fluorescence microscope. \% tail DNA was measured for 50 randomly chosen cells per slide using the Comet Analyzer, and the median \% tail DNA for 50 cells per slide was calculated. The average median for 2 slides was used as the DNA damage parameter for each animal. Cells with heads that were extremely small (\% tail DNA $\geq 90 \%$, "hedgehogs") or irregularly shaped due to cytotoxicity, and which thus deviated substantially from the comet shape, were excluded from the analysis.

As indicated above, for Study 2, Method 2 was adjusted to match the LMA concentrations of Method 1. For Study 3, it was adjusted to match the LMA concentrations and DNA unwinding and electrophoresis times of Method 1 (see Table 1).

\section{Study1: Comparison of the original methods and image analyzers}

Methods 1 and 2 were conducted using tissue from the same animals. Four slides were prepared from each animal for each method, and two of the four slides were analyzed using each analyzer. The sensitivity of the two methods to detect the genotoxicity of a positive control substance (EMS) was evaluated by comparing the mean $\%$ tail DNA between the negative control and EMS-treatment groups for both analyzers.

\section{Study 2: Matching of LMA concentrations}

In this approach, the LMA concentrations used in Method 2 were adjusted to those used in the standard protocol (Method 1), i.e., 0.45\% LMA was used for the second layer and $0.5 \%$ LMA was used for the third layer (see Table 1). All other parameters remained the same, and all comparisons were carried out as in Study 1.

\section{Study 3: Matching LMA concentrations and DNA unwinding and electrophoresis times}

The LMA concentrations and DNA unwinding and electrophoresis times used in Method 2 were adjusted to those used in Method 1 (see Table 1). All other parameters remained the same, and all comparisons were carried out as in Study 1.

\section{Statistical analysis}

The median per each slide was calculated, and the average of these two median values was taken as mean \% tail DNA per animal. For Methods 1 and 2, mean \% tail DNA values, as measured by the Comet Assay IV or Comet Analyzer, were compared between the negative control and EMS-treatment groups. The homogeneity of the means was assessed using the $F$-test. Homoscedastic data were analyzed using a one sided Student's $t$-test, and heteroscedastic data were analyzed with a one sided Aspin-Welch's $t$-test. 
Table 1 Differences in the conditions of Studies 1, 2, and 3

\begin{tabular}{|c|c|c|c|}
\hline Different conditions & Study 1 & Study 2 & Study 3 \\
\hline LMA concentrations & Method 1: $0.45 \& 0.5 \%$ & Method 1: $0.45 \& 0.5 \%$ & Method 1: $0.45 \& 0.5 \%$ \\
\hline (2nd and 3rd layers) & Method 2: $0.7 \& 0.7 \%$ & Method 2: $0.45 \& 0.5 \%$ & Method 2: $0.45 \& 0.5 \%$ \\
\hline \multirow[t]{2}{*}{ Unwinding time } & Method 1: $20 \mathrm{~min}$ & Method 1: $20 \mathrm{~min}$ & Method 1: $20 \mathrm{~min}$ \\
\hline & Method 2: 10 min & Method 2: $10 \mathrm{~min}$ & Method 2: $\underline{20 \mathrm{~min}}$ \\
\hline \multirow[t]{2}{*}{ Electrophoresis time } & Method 1: $20 \mathrm{~min}$ & Method 1: $20 \mathrm{~min}$ & Method 1: $20 \mathrm{~min}$ \\
\hline & Method 2: $15 \mathrm{~min}$ & Method 2: $15 \mathrm{~min}$ & Method 2: $\underline{20 \mathrm{~min}}$ \\
\hline \multirow[t]{2}{*}{ SMA concentration } & Method 1: 1\% & No change & No change \\
\hline & Method 2: $0.7 \%$ & & \\
\hline \multirow[t]{8}{*}{ Mincing buffer and method } & Method 1: & No change & No change \\
\hline & $20 \mathrm{mM}$ EDTA- $2 \mathrm{Na}$ and $10 \%$ DMSO & & \\
\hline & in HBSS $\left(\mathrm{Ca}^{2+}-, \mathrm{Mg}^{2+}\right.$-free, and phenol & & \\
\hline & red-free), at $\mathrm{pH} 7.5$ & & \\
\hline & Method 2: & & \\
\hline & $30 \mathrm{mM}$ EDTA-2Na and $0.9 \%(\mathrm{w} / \mathrm{v})$ & & \\
\hline & $\mathrm{KCl}$ at $\mathrm{pH} 7.5$ & & \\
\hline & $\begin{array}{l}\text { Both Methods } 1 \text { and } 2 \text { use scissors for } \\
\text { mincing. }\end{array}$ & & \\
\hline \multirow[t]{8}{*}{ Lysing solution } & Method 1: & No change & No change \\
\hline & $2.5 \mathrm{M} \mathrm{NaCl}, 100 \mathrm{mM}$ EDTA-2Na, 10 & & \\
\hline & $\mathrm{mM}$ Tris, $1 \%$ Triton $\mathrm{X}-100$, and $10 \%$ & & \\
\hline & DMSO at pH 10 & & \\
\hline & Method 2: & & \\
\hline & $2.5 \mathrm{M} \mathrm{NaCl}, 100 \mathrm{mM}$ EDTA-2Na, 10 & & \\
\hline & $\mathrm{mM}$ Tris, $1 \%$ Triton $\mathrm{X}-100,10 \%$ & & \\
\hline & $\begin{array}{l}\text { DMSO, and } 1 \% \text { sodium lauroyl } \\
\text { sarcosinate }(\mathrm{w} / \mathrm{v}) \text {, at } \mathrm{pH} 10\end{array}$ & & \\
\hline \multirow[t]{2}{*}{ Staining reagent } & Method 1: SYBR Gold & No change & No change \\
\hline & Method 2: EtBr & & \\
\hline
\end{tabular}

\section{Results}

All data are shown in Table 2. In all studies, the values of \% tail DNA were significantly higher in the EMS-treatment group than in the PS negative control group. Typical comet images obtained using each method are presented in Figs. 1 and 2. The images on the left show typical results for the negative control group, while the ones on the right show typical results for the EMS-treatment group. In EMS-treatment group, DNA migration was observed using both methods, but the effect tended to be clearer with Method 1 .

Table 2 Comet assay results for all studies

\begin{tabular}{|c|c|c|c|c|c|}
\hline \multirow[t]{2}{*}{ Protocol } & \multirow[t]{2}{*}{ Analyzer } & \multirow{2}{*}{$\begin{array}{l}\text { Test } \\
\text { substance }\end{array}$} & \multicolumn{3}{|c|}{ Mean $\%$ tail DNA \pm SD } \\
\hline & & & Study 1 & Study 2 & Study 3 \\
\hline \multirow[t]{4}{*}{ Method 1} & \multirow[t]{2}{*}{ Comet Assay IV } & PS & $2.25 \pm 0.58$ & $1.48 \pm 0.36$ & $1.71 \pm 0.76$ \\
\hline & & EMS & $46.36 \pm 5.78^{\# \#}$ & $27.45 \pm 11.89^{\#}$ & $27.03 \pm 1.41^{* *}$ \\
\hline & \multirow[t]{2}{*}{ Comet Analyzer } & PS & $4.04 \pm 0.13$ & $3.51 \pm 0.42$ & $1.34 \pm 0.18$ \\
\hline & & EMS & $35.12 \pm 6.66^{\# \#}$ & $18.54 \pm 3.37^{\# \#}$ & $20.40 \pm 4.41^{\# \#}$ \\
\hline \multirow[t]{4}{*}{ Method 2} & \multirow[t]{2}{*}{ Comet Assay IV } & PS & $6.53 \pm 4.34$ & $3.39 \pm 3.59$ & $2.78 \pm 1.16$ \\
\hline & & EMS & $21.49 \pm 13.05^{*}$ & $12.54 \pm 5.47^{*}$ & $25.57 \pm 7.92^{\# \#}$ \\
\hline & \multirow[t]{2}{*}{ Comet Analyzer } & PS & $4.19 \pm 1.29$ & $2.97 \pm 0.52$ & $4.37 \pm 1.84$ \\
\hline & & EMS & $8.56 \pm 1.92^{* *}$ & $11.05 \pm 3.08^{\# \#}$ & $15.34 \pm 4.76^{* *}$ \\
\hline
\end{tabular}

Statistical analyses were conducted between the EMS-treatment and negative control groups for each of the method/analyzer combinations

$S D$ standard deviation, PS physiological saline, EMS ethyl methanesulfonate

${ }^{*} p<0.05,{ }^{* *} p<0.01$ (Student's $t$-test)

$\# p<0.05, \# \# p<0.01$ (Aspin-Welch's $t$-test) 

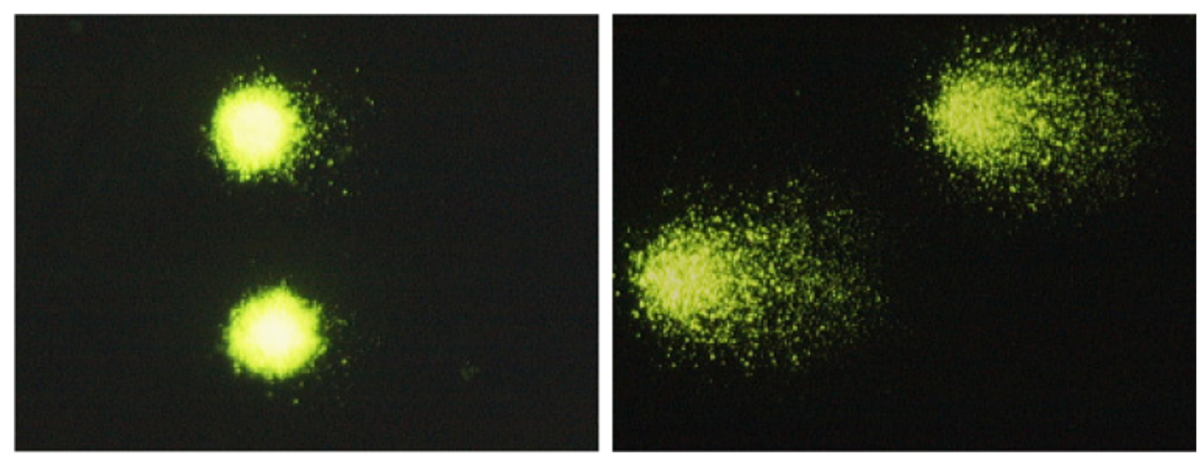

Fig. 1 Typical comet images observed with SYBR Gold staining (Method 1)

\section{Study 1}

Study 1 compared the mean \% tail DNA obtained using the two original methods. In Method 1 using the Comet Assay IV, the values of \% tail DNA in the negative control and EMS-treatment groups were 2.25 and 46.36, respectively, an approximately 20.6-fold difference. For the Comet Analyzer, the values of \% tail DNA in the negative control and EMS-treatment groups were 4.04 and 35.12, respectively, an approximately 8.7-fold difference.

In Method 2 using the Comet Assay IV, the values of $\%$ tail DNA in the negative control and EMS-treatment groups were 6.53 and 21.49, respectively, an approximately 3.3-fold difference. For the Comet Analyzer, the values of \% tail DNA in the negative control and EMS-treatment groups were 4.19 and 8.56, respectively, an approximately 2 -fold difference.

\section{Study 2}

Study 2 compared the mean \% tail DNA obtained when the LMA concentrations in Method 2 were standardized to those used in Method 1. In Method 1 using the Comet Assay IV, the values of \% tail DNA in the negative control and the EMS-treatment groups were 1.48 and 27.45, respectively, an approximately 18.5-fold difference. For the Comet Analyzer, the values of \% tail
DNA in the negative control and EMS-treatment groups were 3.51 and 18.54 , respectively, an approximately 5.3-fold difference.

In Method 2 using the Comet Assay IV, the values of $\%$ tail DNA in the negative control and EMS-treatment groups were 3.39 and 12.54, respectively, an approximately 3.7-fold difference. For the Comet Analyzer, the values of \% tail DNA in the negative control and EMS-treatment groups were 2.97 and 11.05, respectively, an approximately 3.7 -fold difference.

\section{Study 3}

Study 3 compared the mean \% tail DNA obtained when the LMA concentrations and DNA unwinding and electrophoresis times of Method 2 were standardized to those used in Method 1. In each group (treatment and control), there was a single slide from a single animal in which the cells had broken during analysis with the Comet assay IV, probably because the LMA had not solidified sufficiently. These slides were excluded from the analysis. As a result, the mean \% tail DNA for the affected animals was calculated from a single slide (i.e., the median per one slide was used for the analysis) In Method 1 using the Comet Assay IV, the values of \% tail DNA in the negative control and EMS-treatment groups were 1.71 and 27.03, respectively, an approximately
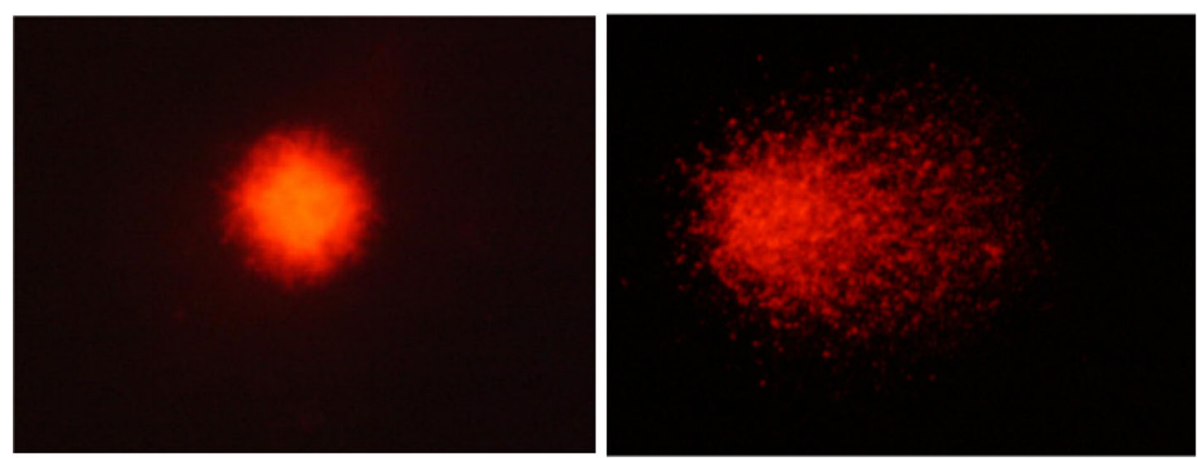

Fig. 2 Typical Comet images observed with EtBr staining (Method 2) 
15.8-fold difference. For the Comet Analyzer, the values of \% tail DNA in the negative control and EMS-treatment groups were 1.34 and 20.40 , respectively, an approximately 15.2 -fold difference.

In Method 2 using the Comet Assay IV, the values of $\%$ tail DNA in the negative control and EMS-treatment groups were 2.78 and 25.57, respectively, an approximately 9.2-fold difference. For the Comet Analyzer, the values of \% tail DNA in the negative control and EMS-treatment groups were 4.37 and 15.34, respectively, an approximately 3.5 -fold difference.

\section{Discussion}

EMS is used as a positive genotoxic control in the standard protocol for the international validation of the in vivo comet assay and the OECD test guideline (TG489) $[10,14]$. A statistically significant positive result for EMS is necessary to confirm the accuracy of the test. Here, the comparison of results between the EMS-treatment and negative control groups demonstrated that the mean $\%$ tail DNA was significantly higher in the treatment group than in the control group, irrespective of the method or image analyzer used. This confirms that both methods have the potential to detect genotoxic substances.

Study 1 found that, for the EMS-treatment group, the mean \% tail DNA was lower for Method 2 than for Method 1, and the mean \% tail DNA of the negative control group was relatively high. Thus, the difference was slight between the negative control and EMS-treatment groups in Method 2 using the Comet Analyzer. The mean $\%$ tail DNA values of all negative control groups, including the results of Studies 2 and 3, were within an acceptable range $(1-8 \%)$ for the in vivo comet assay international validation standards [15]; however, the ratio of mean \% tail DNA (3.3 and 2) between the negative control and EMStreatment groups in Method 2 was much smaller than that in Method 1 (20.6 and 8.7). The ratio between the negative control and EMS-treatment groups was in the range of 2-18.5 for all of the participating institutes [15]. Its low sensitivity for the detection of positive substances was of concerned because there is a risk that the ratio of $\%$ tail DNA would be lower than 2 depending on the tests performed using Method 2. In contrast, the ratio between the negative control and EMS-treatment groups was 20.6 in data of the Comet assayIV in Method 1, which was higher than the above range; however, the absolute value of \% tail DNA was 46.36, which was lower than the predicted maximum mean value of the EMS-treatment group (approximately 70 or more) in the in vivo comet assay international validation study [15]. In other words, this high absolute value was not abnormal, and the higher ratio was due to the low value of the negative control group; thus, it was considered that Method 1 had sufficient sensitivity to detect genotoxic substances.

This low sensitivity of Method 2 was likely due to the LMA concentrations and DNA unwinding and electrophoresis times. This is because when the concentration of LMA is high, it is difficult for DNA fragments to pass through the gel, and when the unwinding time is short, there is an insufficient amount of unwound doublestranded DNA, and the DNA migrates less easily due to the short electrophoresis time. The impact of these three parameters has already been evaluated for the in vitro comet assay, and an increase in \% tail DNA values in response to decreased agarose concentrations and extended unwinding and electrophoresis times has been reported $[16,17]$. From these results, in the case of a test substance such as acrylamide, for which a clear positive result is difficult to obtain using the in vivo comet assay, despite it being a known genotoxic carcinogen, it is of concern that the potential differences between the results of Methods 1 and 2 may occur due to this low sensitivity for a positive control substance as a consequence of unsuitable dose-settings [15, 18, 19]. Since the test substances was administered at the maximal tolerated dose in the in vivo comet assay, there was an upper limit to the dose. In order to maintain a certain detection sensitivity for a limited administration dose, the results of Studies 2 and 3 indicated that the LMA concentrations and DNA unwinding and electrophoresis times of Method 1 are appropriate.

An electrophoresis voltage of 0.7 to $1.0 \mathrm{~V} / \mathrm{cm}$ has been recommended [4]. While a voltage outside the recommended range would likely affect the results, it is unlikely that variation within this range would have significant impact. Similarly, at a constant voltage, variation of the current between 200 to $400 \mathrm{~mA}$ is not likely to have meaningful effect on the results [17]. Our experiments showed very clearly that by standardizing the LMA concentrations and DNA unwinding and electrophoresis times, highly comparable results can be obtained from both methods without standardizing the remaining parameters of the in vivo comet assay. However, several other parameters varied between the two methods, including the SMA concentration used for the bottom layer of the slides, the composition of the mincing buffer and lysing solution, and the DNA staining method. It is likely that these parameters could affect the judgement of a positive result, with the exception of SMA, which was not in immediate contact with the cells. In Studies 1, 2, and 3, the mean \% tail DNA values in the EMS-treatment group assessed using the Comet Analyzer tended to be low. The dark red fluorescence of $\mathrm{EtBr}$ was weaker than the fluorescence of SYBR Gold in microscopic observations, so it was suspected that this weak fluorescence might have affected the sensitivity to detect the tail of the comet. As it 
was not possible to clarify the effects of the different compositions of the mincing buffer and lysing solution on the results, it is likely that there is room for further research in the future. Therefore, in order to improve the detection sensitivity of genotoxic substances, it is considered preferable that these conditions should also be matched to those of Method 1 wherever possible.

Regarding the image analyzers, overall, the sensitivity of the Comet Assay IV seemed to be slightly higher than that of the Comet Analyzer from the results of this study. Especially, the mean \% tail DNA (8.56\%) of the EMS-treatment group was extremely low for Method 2 in Study 1. It was suggested that this low \% tail DNA value could be improved by using SYBR Gold as the fluorescence stain. However, upon standardization of the experimental parameters in Study 3, the difference in the results obtained using the Comet Assay IV and Comet Analyzer was small, and the choice of image analyzer had little impact.

Thus, we conclude that, by standardizing LMA concentrations and DNA unwinding and electrophoresis times at least, DNA damage can be evaluated with equal sensitivity using different test protocols and image analyzers. While, in order to decrease the incidence of false negative results, we consider it desirable to conduct these tests using a method with high sensitivity for genotoxic substances, such as like the standard protocol for the in vivo comet assay international validation.

\section{Abbreviations}

DPBS: Dulbecco's phosphate-buffered saline; EMS: Ethyl methanesulfonate; EtBr: Ethidium bromide; LMA: Low melting agarose gel; OECD: Organisation for Economic Co-operation and Development; PS: Physiological saline; SMA: Standard melting agarose gel

\section{Acknowledgements}

The authors thank all students in the Food Hygiene Research Laboratory of University of Shizuoka for their technical help.

\section{Authors' contributions}

TK and RI designed and conducted the study, and analyzed the data. YS provided technical assistance. TK drafted the manuscript, and SM and MT refined the manuscript. All authors read and approved the final manuscript.

\section{Competing interests}

The authors declare that they have no competing interest.

\section{Publisher's Note}

Springer Nature remains neutral with regard to jurisdictional claims in published maps and institutional affiliations.

\section{Author details}

${ }^{1}$ Life Science Research Institute, Kumiai Chemical Industry Co., Ltd, 3360 Kamo, Kikugawa-shi, Shizuoka 439-0031, Japan. ${ }^{2}$ School of Food and Nutritional Sciences, University of Shizuoka, 52-1 Yada, Suruga-ku, Shizuoka 422-8526, Japan.
Received: 2 August 2017 Accepted: 21 December 2017

Published online: 07 February 2018

References

1. Singh NP, MT MC, Tice RR, Schneider EL, et al. Exp Cell Res. 1988;175: 184-91.

2. Fairbairn DW, Olive PL, O'Neill KL. The comet assay: a comprehensive review. Mutat Res. 1995;339:37-59.

3. Tsuda S, Matsusaka N, Madarame H, Miyamae Y, Ishida K, Satoh M, Sekihashi K, Sasaki YF. The alkaline single cell electrophoresis assay with eight mouse organs: results with 22 mono-functional alkylating agents (including 9 dialkyl N-nitrosoamines) and 10 DNA crosslinkers. Mutat Res. 2000;467:83-98.

4. Tice RR, Agurell E, Anderson D, Burlinson B, Hartmann A, Kobayashi H, Miyamae Y, Rojas E, Ryu JC, Sasaki YF. Single cell gel/comet assay: guidelines for in vitro and in vivo genetic toxicology testing. Environ Mol Mutagen. 2000;35:206-21.

5. Merk O, Reiser K, Speit G. Analysis of chromate-induced DNA-protein cross links with the comet assay. Mutat Res. 2000;471:71-80.

6. McKelvey-Martin VJ, Green MH, Schmezer P, Pool-Zobel BL, De Méo MP, Collins A. The single cell gel electrophoresis assay (comet assay): a European review. Mutat Res. 1993:288:47-63.

7. Burlinson B, Tice RR, Speit G, Agurell E, Brendler-Schwaab SY, Collins AR, Escobar P, Honma M, Kumaravel TS, Nakajima M, Sasaki YF, Thybaud V, Uno $Y$, Vasquez M, Hartmann A. Fourth international workgroup on genotoxicity testing: results of the in vivo comet assay workgroup. Mutat Res. 2007;627: $31-5$

8. Hartmann A, Agurell E, Beevers C, Brendler-Schwaab S, Burlinson B, Clay P, Collins A, Smith A, Speit G, Thybaud V, Tice RR. Recommendations for conducting the in vivo alkaline comet assay. Mutagenesis. 2003;18:45-51.

9. Olive PL, Banáth JP, Durand RE. Heterogeneity in radiation-induced DNA damage and repair in tumor and normal cell using the "comet" assay. Radiat Res. 1990;122:86-94.

10. The Validation Management Team. International validation of the in vivo rodent alkaline comet assay for the detection of genotoxic carcinogens (Version 14.2). Nov 2009 revised.

11. Ogawa I, Furukawa S, Tanaka Y, Abe M, Usuda K, Hayashi S, Onitsuka H. Study on the in vivo comet assay using rat uteri. Genes Environ. 2007;29: 159-62.

12. Nakajima M, Ueda M, Yamakage K, Nakagawa $Y$, Nakagawa M, Ohyama W, Omori T, Asano N, Hayashi M, Uno Y. Tissue sample preparation for in vivo rodent alkaline comet assay. Genes Environ. 2012;34:50-4.

13. Wada K, Ohnuma A, Kojima S, Yoshida T, Matsumoto K. A comparison of cell-collecting methods for the comet assay in urinary bladders of rats. Mutat Res. 2012;742:26-30

14. OECD. Test Guideline TG489. In: Vivo Mammalian Alkaline Comet Assay Accepted 26 Sep 2014.

15. Uno Y, Kojima H, Omori T, Corvi R, Honma M, Schechtman LM, Tice RR, Burlinson B, Escobar PA, Kraynak AR, Nakagawa Y, Nakajima M, Pant K, Asano N, Lovell D, Morita T, Ohno Y, Hayashi M. JaCVAM-organized international validation study of the in vivo rodent alkaline comet assay for the detection of genotoxic carcinogens: I. Summary of pre-validation study results. Mutat Res Genet Toxicol Environ Mutagen. 2015;786-788:3-13.

16. Ersson C, Möller $\mathrm{L}$. The effects on DNA migration of altering parameters in the comet assay protocol such as agarose density, electrophoresis conditions and durations of the enzyme or the alkaline treatments. Mutagenesis. 2011;26:689-95.

17. Azqueta A, Gutzkow KB, Brunborg G, Collins AR. Towards a more reliable comet assay: Optimising agarose concentration, unwinding time and electrophoresis conditions. Mutat Res. 2011;742:41-5.

18. Recio L, Hobbs C, Caspary W, Witt KL. Dose-response assessment of four genotoxic chemicals in a combined mouse and rat micronucleus and comet assay protocol. J Toxicol Sci. 2010;35:149-62.

19. Dobrovolsky VN, Pacheco-Martinez MM, McDaniel LP, Pearce MG, Ding W. In vivo genotoxicity assessment of acrylamide and glycidyl methacrylate. Food Chem Toxicol. 2016:87:120-7. 